\title{
ERpS294 is a biomarker of ligand or mutational ERa activation and a breast cancer target for CDK2 inhibition
}

\author{
Gary K. Scott ${ }^{1, *}$, David Chu ${ }^{2, *}$, Ravneet Kaur ${ }^{1}$, Julia Malato ${ }^{3}$, Daniel E. Rothschild ${ }^{1}$, \\ Katya Frazier ${ }^{1}$, Serenella Eppenberger-Castori ${ }^{4}$, Byron Hann ${ }^{3}$, Ben Ho Park ${ }^{2}$, and \\ Christopher C. Benz ${ }^{1,3}$ \\ ${ }^{1}$ Buck Institute for Research on Aging, Novato, CA, USA \\ 2 The Johns Hopkins University School of Medicine, Baltimore, MD, USA \\ ${ }^{3}$ Helen Diller Family Comprehensive Cancer Center, University of California, San Francisco, CA, USA \\ ${ }^{4}$ Institute for Pathology, Basel University Hospital, Basel, Switzerland \\ * These authors made equal contribution to this work \\ Correspondence to: Christopher C. Benz, email: cbenz@buckinstitute.org \\ Keywords: ERa phosphorylation, ESR 1 mutations, cyclin-dependent kinase-2 inhibitors \\ Received: September 15,2016 Accepted: September 25, $2016 \quad$ Published: October 18, 2016
}

Copyright: Scott et al. This is an open-access article distributed under the terms of the Creative Commons Attribution License 3.0 (CC BY 3.0), which permits unrestricted use, distribution, and reproduction in any medium, provided the original author and source are credited.

\section{ABSTRACT}

ER $\alpha$ phosphorylation at hinge site S294 (pS294) was recently shown to be essential for ER-dependent gene transcription and mediated by an unknown cyclindependent kinase (CDK). This study was undertaken to identify the exact CDK pathway mediating pS294 formation, and to determine if this phosphorylation event occurs with, and can be targeted to treat, the ligand-independent growth of breast cancers expressing endocrine-refractory ESR1 mutations. Using a newly developed anti-pS294 monoclonal antibody, a combination of CDK specific siRNA knockdown studies and a broad panel of CDK selective inhibitors against ligand (E2)-stimulated MCF7 cells, we first identified CDK2 as the primary mediator of pS294 formation and showed that CDK2-selective inhibitors like Dinaciclib,s but not CDK4/6 inhibitors like Palbociclib, can selectively prevent pS294 formation and repress ER-dependent gene expression. We then expressed the ER-activating mutations ERmut(Y537S) and ERmut(D538G) in MCF7 cells, and demonstrated their ability to induce ligandindependent and tamoxifen-resistant growth, associated with constitutive and CDK2dependent pS294 expression. Following robust growth of E2-independent and TAMresistant MCF7mutER(Y537S) tumors in vivo, nude mice were also treated with either Dinaciclib or Palbociclib at doses and injection schedules unable to retard tumor growth as single agents; the TAM plus Palbociclib combination arrested further tumor growth without affecting pS294 formation, while the TAM plus Dinaciclib combination produced tumor regression associated with loss of pS294 expression. These findings, and our proposed mechanistic model, provide new rationale for the clinical evaluation of CDK2 inhibitors given in combination with endocrine agents as a new treatment strategy against ESR1 mutation expressing breast cancers.

\section{INTRODUCTION}

Despite estrogen receptor-alpha (ER $\alpha)$ being one of the earliest known and best validated protein targets for cancer therapeutics, our incomplete knowledge about its full molecular structure, mechanism of action, and multiple roles in intracellular signaling and transcriptional control of both normal organ development and malignant tumor growth continues to foster an industry of basic and translational research on this nuclear receptor system [1, 2]. Not least among our knowledge gaps, and prompted largely by the pressing need for more biomarker specificity to predict clinical responsiveness to ER-targeted endocrine 
agents like antiestrogens (e.g. tamoxifen) and aromatase inhibitors, is understanding the functional role of the many posttranslational modifications (PTMs) now being documented across this $\sim 67 \mathrm{kDa}$ nuclear receptor protein, including its sites of phosphorylation, methylation, acetylation, sumoylation and ubiquitination. Indeed, the overall constellation of PTMs in tumor-expressed ER $\alpha$ may be considered a molecular code reflecting its mode of intracellular receptor activation (e.g. ligand-dependent, ligand-independent) and response to cross-talk, its protein conformation, intracellular localization, and transcriptional competency [3].

$\mathrm{ER} \alpha$ phosphorylation, first described over three decades ago, is unquestionably the best studied of all its PTMs, particularly those most commonly observed serine (S) phosphorylation events in ER-positive breast cancer cells detectable by either site-specific antibodies or modern mass spectrometry approaches [4-7]: phosphorylation of the receptor's N-terminal (AF-1) domain at S118 and S167 [8, 9], and its more recently described hinge and ligand-binding domain (LBD) phosphorylation at S294 and S305 [10, 11]. While preclinical evidence indicates that each of these four different phosphorylation events regulate $\mathrm{ER} \alpha$ transcriptional activity to some degree, more limited clinical evidence suggests that their prognostic and predictive values are site-specific and not equivalent, with pS118 and pS167 tumor immunoreactivity associated with antiestrogen responsiveness while pS305 tumor immunoreactivity is associated with antiestrogen resistance [8-10, 12, 13]. One reasonable explanation for their different clinical values as individual biomarkers is that each of these ER $\alpha$ phosphorylation events is mediated by a different set of signal-activated kinases $[3,7,11]$, with $\mathrm{pS} 118$ and $\mathrm{pS} 167$ induced by kinases activated during both ligand-dependent and ligandindependent ER $\alpha$ activation (e.g. IKK $\alpha$, MAPK, S6K1, AKT, and RSK), while pS305 is induced by other kinases associated with ligand-independent activation (e.g. PAK1 and PKA), and pS294 is induced by yet another kinase family associated with ligand-dependent $\operatorname{ER} \alpha$ activation (CDK). How these different site-specific serine kinases become recruited to the receptor in response to different types of ER $\alpha$ activating stimuli remains largely unknown. Moreover, with the important recent finding of recurrent LBD hotspot mutations in ESR1 (encoding ERmut) arising during metastatic progression of endocrine-refractory ERpositive breast tumors [14-16], coupled with structural evidence that these ESR 1 mutations constitutively activate ERmut in a ligand-independent (and ligand-excluding) manner $[17,18]$, there is no information yet available about the role, if any, receptor phosphorylation may play when breast cancers become driven by ESR 1 mutations like Y537S or D538G.

We previously employed mass spectrometry to detect pS294 expression in various ER-positive breast cancer cell line models subjected to agonistic ligand stimulation [11]; notably, unlike pS118 which can be induced by either ligand or growth factor stimulation, pS294 was shown to be the only phosphorylation site on ER $\alpha$ induced exclusively by ligand binding. Additionally, the mass spectrometry study also demonstrated that pS294 formation is mediated by a serine/threonine protein kinase from the cyclin-dependent kinase (CDK) family [11]; however, we did not know which CDK from that 20-member kinase family actually phosphorylates ER $\alpha$ at that hinge site, a clinically relevant question since CDK4/6-selective inhibitors are now approved and being developed to treat ER-positive breast cancers [19], while other CDK1/2-selective inhibitors are being developed to treat other types of malignancies [20-22]. Therefore, using a newly developed anti-pS294 rabbit monoclonal antibody, the present study was undertaken to identify the exact CDK pathway mediating pS294 induction and to explore the potential role of $\mathrm{pS} 294$ formation in driving the ligand-independent growth of breast cancers expressing endocrine-refractory ESR 1 mutations.

\section{RESULTS}

\section{pS294 immunoreactivity, induction kinetics, and variable expression in ER-positive human breast tumors}

To demonstrate the immunospecificity of our newly developed anti-pS294 rabbit monoclonal, COS7 cells were transfected with either wildtype (wt) ER $\alpha$, $\mathrm{ER} \alpha$ mutated at S294 (S294A), or ER $\alpha$ mutated at S118 (S118A). As shown in Figure 1A, specific pS294 induction is seen 45 min after E2 stimulating the wt or S118A transfected COS-7(ER) cells, but not in stimulated cells transfected with S294A. While detection of endogenously expressed pS294 and pS118 are readily seen by first immunoprecipitating total $\mathrm{ER} \alpha$ and then probing the immunoprecipitate for phosphorylated forms of $\operatorname{ER} \alpha$, we have also shown that our rabbit monoclonal can be used to first immunoprecipitate pS294 from cell or tumor lysates (as shown in Figure 1C, inset). Figure 1B shows the ligand induction kinetics of pS294 relative to $\mathrm{pS} 118$ in wt MCF7 cells that were grown in estrogen-free media and stimulating with E2 $(10 \mathrm{nM})$ before extracting and analyzing cell lysates (as in Figure 1A) for pS294, $\mathrm{pS} 118$, and total ER $\alpha$. In this model system, while pS118 induction is detectable by $5 \mathrm{~min}$ and peaks within $10 \mathrm{~min}$, pS294 induction is more delayed, appearing at $10 \mathrm{~min}$ and not peaking for at least $45 \mathrm{~min}$.

To look for evidence of pS294 expression in human breast tumors, we surveyed 18 cryobanked ER-positive breast tumor samples. Given some evidence that pS118 and pS305 tumor expression show opposite clinical associations with antiestrogen responsiveness $[8,10]$, we 
Table 1: CDK inhibitors and their target specificities, evaluated in this study.

\begin{tabular}{|l|l|}
\hline CDK Inhibitors & Target Selectivity $\left(\text { IC }_{\mathbf{5}}\right)^{*}$ \\
\hline Dinaciclib/SCH-727965 & CDK1 $(3 \mathrm{nM})$, CDK2 $(1 \mathrm{nM})$, CDK5 $(1 \mathrm{nM})$, CDK9 $(4 \mathrm{NM})$ \\
\hline SNS-032 & CDK2 $(38 \mathrm{nM})$, CDK7 $(62 \mathrm{nM})$, CDK9 $(4 \mathrm{nM})$ \\
\hline BMS-265246 & CDK1 $(6 \mathrm{nM})$, CDK2 $(9 \mathrm{nM})$ \\
\hline JNJ-7706621 & CDK1 $(9 \mathrm{nM})$, CDK2 $(4 \mathrm{nM})$ \\
\hline CYC065 & CDK2 $(5 \mathrm{nM})$, CDK9 $(26 \mathrm{nM})$ \\
\hline Palbociclib/PD-0332991 & CDK4 $(11 \mathrm{nM})$, CDK6 $(16 \mathrm{nM})$ \\
\hline
\end{tabular}

* Half maximal inhibitory concentrations $\left(\mathrm{IC}_{50}\right)$ of drug assayed in cell-free systems; all values from Selleckchem.com, except for CYC065 [24].

A.

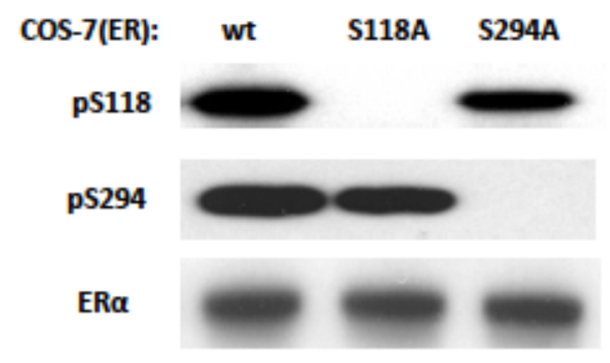

B.

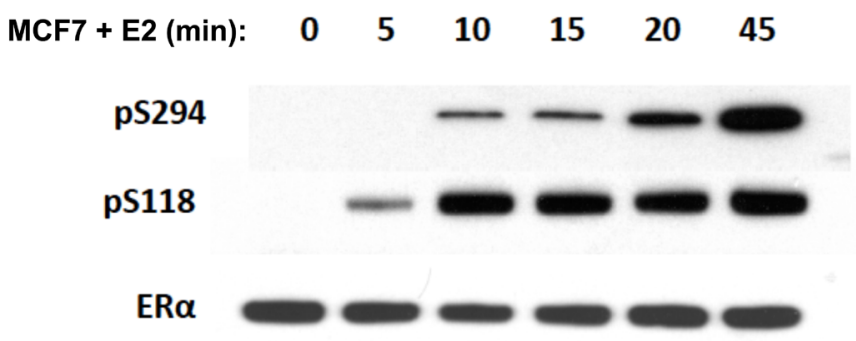

C.

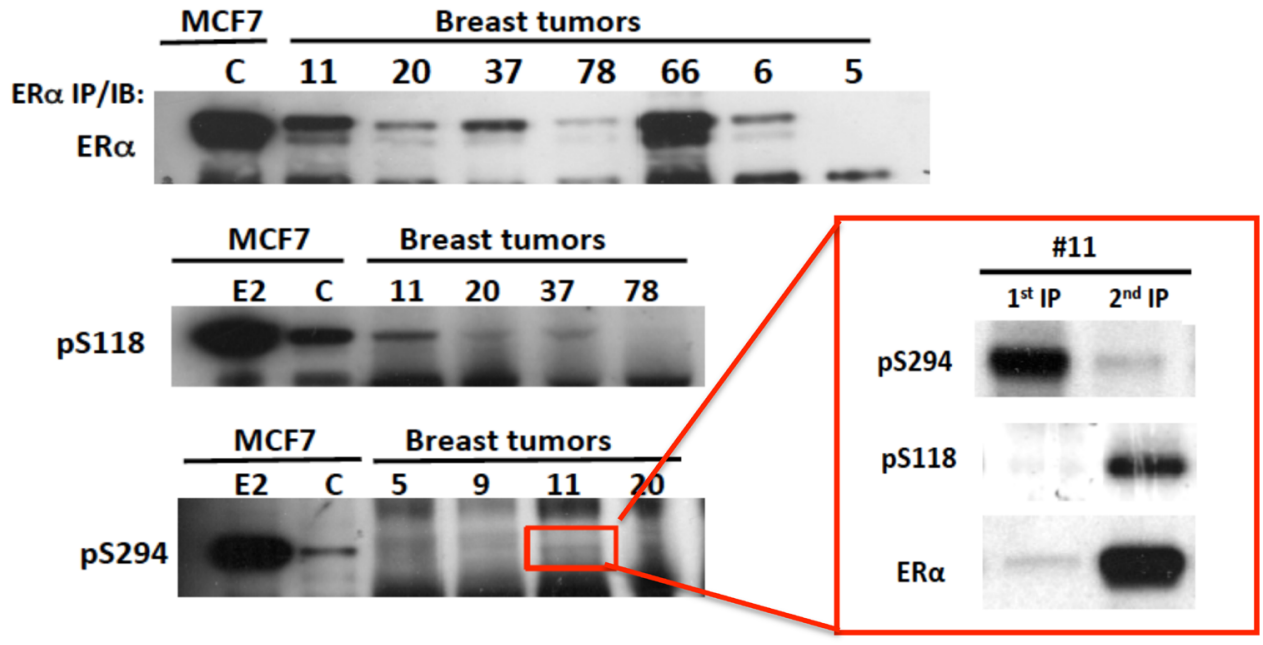

Figure 1: Specific immunoreactivity of pS294, its induction kinetics relative to pS118 in an ER-positive breast cancer cell line (MCF7), and the variable expression of endogenous pS294 found in ER-positive human breast tumors. A. To demonstrate the immunospecificity of a newly developed anti-ERpS294 rabbit monoclonal, COS-7 cells were transfected with either wildtype (wt) ER $\alpha$, ER $\alpha$ mutated at S294 (S294A) or ER $\alpha$ mutated at S118 (S118A); $24 \mathrm{~h}$ after transfection, media was changed to charcoal-stripped serum containing media for 24 hours, followed by E2 treatment at $10 \mathrm{nM}$ for $45 \mathrm{~min}$, and cells were then lysed, ER $\alpha$ immunoprecipitated and probed by western blotting. B. To compare the ligand induction kinetics of pS294 relative to pS118, MCF7 cells grown for $>24 \mathrm{~h}$ in charcoal-stripped media were treated with E2 $(10 \mathrm{nM})$ for the indicated times, ER $\alpha$ was immunoprecipitated and probed via western blot for pS294, pS118, and total ER $\alpha$. C. To compare detection of pS294 expression in representative ER-positive primary breast tumor samples ( $\# 5,6,9,11,20,37,66,78)$ relative to control (C) or E2 (45 min) treated MCF7 cells, whole cell lysates were first immunprecipated (IP) for total ER $\alpha$. and further immunoblotted (IB) for $\mathrm{pS} 294, \mathrm{pS} 118$, and total ER $\alpha$. As shown in the inset for tumor sample \#11, parallel lysate aliquots were first immunoprecipitated for pS294 and that $1^{\text {st }}$ IP immunblotted for pS294, pS118, and total ER $\alpha$ content $\left(1^{\text {st }} \mathrm{IP}\right)$, while the remaining unprecipitated lysate was then immnoprecipitated for total ER $\alpha$ and immunoblotted for $\mathrm{pS} 294, \mathrm{pS} 118$, and total $\mathrm{ER} \alpha\left(2^{\text {nd }} \mathrm{IP}\right)$. 
attempted to compare these phosphorylated forms of ER $\alpha$ with pS294 expression by immunoprecipitating the tumor lysates for total $\mathrm{ER} \alpha$ and then western blotting for total and phosphorylated forms of ER $\alpha$. Two samples failed to show detectable $\mathrm{ER} \alpha$ (samples \#4, 5); and 3 others showed such low total ER $\alpha$ that we could not clearly detect phosphorylated forms (\#6, 20, 78). Figure 1C shows representative results from this tumor survey. From the 13 tumor samples in which some phosphorylated ER $\alpha$ could be detected, pS118 appeared much more prominent than

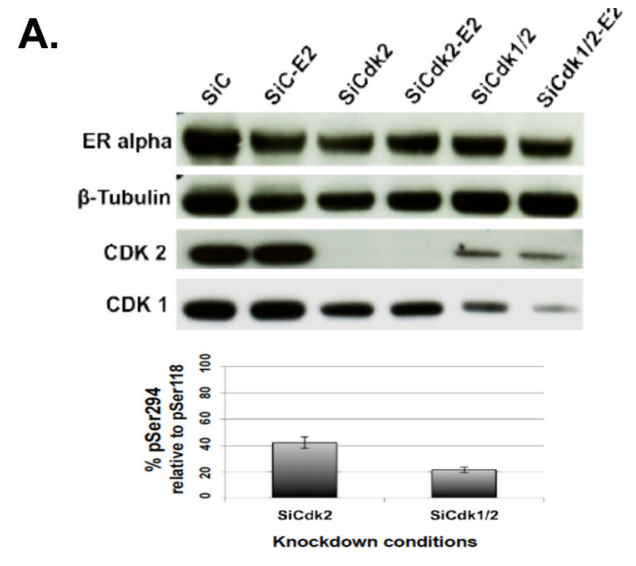

C.

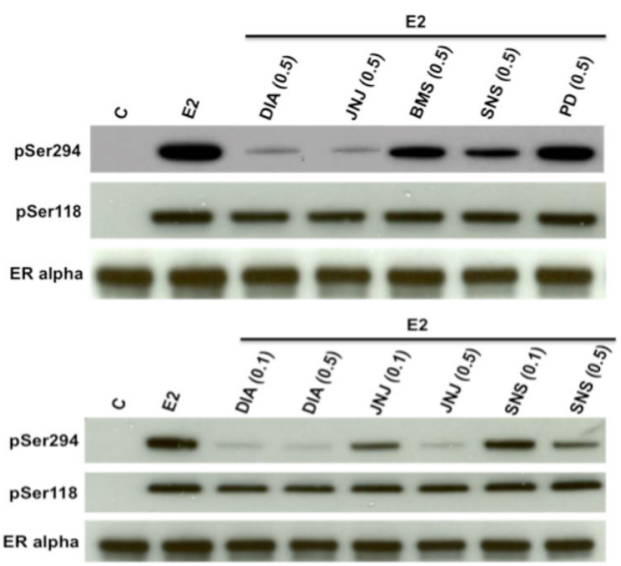

either pS294 or pS305; in 7 of these samples (\#11, 14, 22, 33, 39, 69, 146), pS294 expression appeared greater than pS305 while in 6 samples $(\# 9,13,26,37,46,66)$ the reverse was apparent. Given the barely detectable pS294 and pS305 expression by this approach, we re-extracted a few residual tumor samples and first immunoprecipitated them for pS294 (we could not continue our pS305 analysis due to commercial withdrawal of the anti-pS305 monoclonal); this reverse approach proved to be the more sensitive means of assessing pS294 expression in either

B.

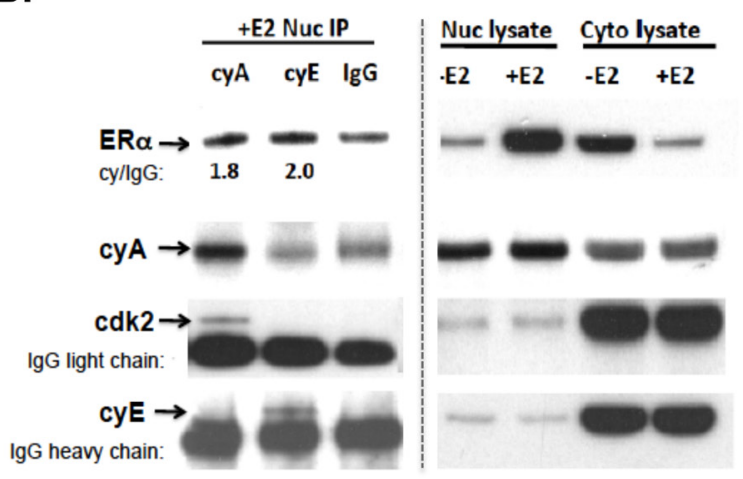

D.

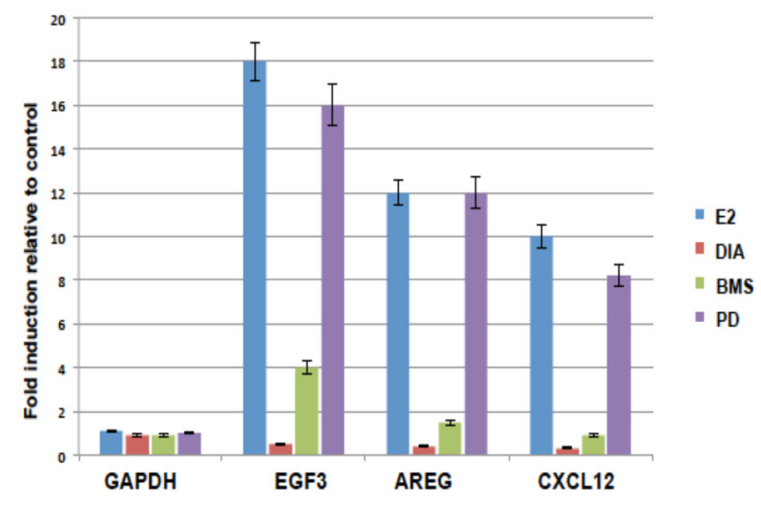

Figure 2: ERa ligand binding triggers rapid association with cyclin A/E-associated CDK2, whose suppression or enzymatic inhibition not only prevents pS294 formation but also the transcription of ERa inducible genes (EGF3, AREG, CXCL12). A. Knockdown of CDK1 and/or CDK2 was performed on replicate wells of MCF7 cells transfected with either control (C), CDK2 or CDK1/2 targeted siRNA; $24 \mathrm{~h}$ later cultures were changed to phenol red-free media containing 10\% charcoal-stripped serum and allowed to grow for another $24 \mathrm{~h}$ before treatment with $\mathrm{E} 2(10 \mathrm{nM}$ x $30 \mathrm{~min})$, followed by cell harvesting, protein extraction and western blotting for ER $\alpha, \beta$-tubulin, CDK1 and CDK2 as shown. In parallel, immunoprecipitation of total ER $\alpha$ from the cell lysates was followed by western blotting to detect pS294 and pS118 levels; and densitometry measured band intensities were used to quantitate pS294 levels relative to pS118 levels after knockdown of CDK2 alone (SiCdk2) or combined CDK1/2 knockdown (SiCdk1/2) under E2 exposure, relative to control siRNA (SiC-E2) treatment conditions. The average relative declines $(n=3, \mathrm{SEM})$ in $\mathrm{pS} 294$ (relative to pS118) are shown in the bar graphs below. B. MCF7 cells grown in charcoal stripped and phenol red free media were treated $+/-$ ligand (-E2 or + E2, $10 \mathrm{nM} x$ $30 \mathrm{~min}$ ), gently lysed and nuclei pelleted and extracted, producing cell fractions (Nuc lysate, Cyto lysate) that were immunoblotted for ER $\alpha$, cyclin A2 (cyA), cyclin E (cyE) or CKD2 as shown. In parallel, the E2 treated Nuc lysates were first immunoprecipitated using anti-cyA, anti-cyE, or control anti-IgG and then immunoblotted for ER $\alpha$, cyA, cyE and CKD2. C. MCF7 cultures pretreated for 60 min with either vehicle $(C)$ or the indicated dose $(\mu \mathrm{M})$ of CDK inhibitor $(\mathrm{DIA}=$ Dinaciclib, JNJ $=$ JNJ7706621, BMS $=$ BMS265246, SNS $=$ SNS-032, $\mathrm{PD}=\mathrm{PD} 0332991 /$ Palbociclib) were then stimulated for 20 min with E2 before harvest, protein extraction, ER $\alpha$ immunoprecipitation, and immunoblotting for pS294, pS118, and total ER $\alpha$ as shown. D. MCF7 cells grown in charcoal stripped and phenol red-free media were pretreated for $1 \mathrm{~h}$ with $0.5 \mu \mathrm{M}$ DIA, $1 \mu \mathrm{M}$ PD, or $1 \mu \mathrm{M}$ BMS followed by $6 \mathrm{~h}$ E2 $(10 \mathrm{nM})$ treatment, after which total RNA was extracted and semiquantitative RT-PCR performed to measure fold induction of the ER $\alpha$ inducible genes EGF3, AREG, and CXCL12 relative to the housekeeping gene GAPDH, using previously described primers and methods [11]. 
tumors or cells, as exemplified by tumor sample \#11 (inset Figure 1C).

\section{CDK2 mediates pS294 formation, and CDK2 selective inhibitors repress pS294 and ER- dependent gene expression}

To identify the exact CDK pathway mediating pS294 formation and determine if this could be a therapeutic target, we first employed CDK-specific siRNA knockdown studies and then tested a broad panel of CDK selective inhibitors against ligand (E2)-stimulated MCF7 cells. As shown in Figure 2A, complete knockdown of CDK2 was well tolerated and resulted in $58 \%$ reduction in E2 induced pS294 relative to pS118 expression. CDK1 knockdown was quickly lethal to the MCF7 cells; but, since CDK1 can compensate for loss of CDK2, we attempted to evaluating combined partial knockdown of both mitotic CDKs, CDK1/2, which produced a $78 \%$ reduction in ligand induced $\mathrm{pS} 294$ relative to $\mathrm{pS} 118$. In contrast, knockdown of the non-mitotic CDK9, an additional target of some of the CDK inhibitors studied, had absolutely no impact on E2 induction of pS294 in this same cell system (Supplement Figure S1). Since CDK2 is mitotically activated by cyclins A and E, we looked for the co-association of these cyclins with nuclear $\mathrm{ER} \alpha$ immunoprecipitated after E2 induction of MCF7 cells (Figure 2B). E2 induced nuclear localization of $\mathrm{ER} \alpha$ as expected; however, separation of nuclei from the cytoplasmic fractions left most of the cyclin $\mathrm{E}$ in the latter, presumably not bound to a large enough complex to avoid leaking from the nuclei in these asynchronously growing cells. In contrast, most cyclin A remained in the nuclei and was not only enriched in the nuclear ER $\alpha$ immunoprecipitates but also co-associated with CDK2 (Figure 2B).

To further discriminate between CDK1 and CDK2 loss of function with regard to pS294 formation and to compare with loss of CDK4/6 function, we tested the broad panel of CDK selective inhibitors described in Table 1. As shown in Figure 2C, the ability of four different CDK inhibitors prevented pS294 formation in rank order according to their CDK2 targeting potency $\left(\mathrm{IC}_{50}\right.$ values): Dinaciclib > JNJ-7706621 > SNS-032 and BMS265246, which also appeared independent of their CDK1 selectivity since SNS-032 is at least 10 -fold more potent against CDK2 than CDK1 [23]. To confirm the preferred dependence of pS294 on CDK2 rather than CDK1, a potent new CDK2 inhibitor $>100$-fold more selective for CDK2 than CDK1, CYC065 [24], was shown to prevent pS294 formation almost as efficiently as Dinaciclib in MCF7 and SUM44 cells (Supplement Figure S2). Of note, the clinically approved CDK4/6 inhibitor Palbociclib had no ability to prevent pS294 formation (Figure 2C). Also notable, the potent mitogen activated protein kinase (MAPK) p38 inhibitor, SB203580, is unable to prevent pS294 induction (Supplement Figure S2). Evaluation the same three ER-dependent gene transcripts (EGF3, AREG, CXCL12) that we first showed could be inhibited by mutating the ER $\alpha$ S294 site to prevent its phosphorylation [11], we now show that E2 induction of these genes in MCF7 cells can be prevented by the CDK2 inhibitors, Dinaciclib and BMS-265246, but not by the CDK4/6 inhibitor Palbociclib (Figure 2D). These same CDK2 inhibitors (Dinaciclib, BMS-265246), but not the CDK4/6 inhibitor (Palbociclib), are able to cooperate with tamoxifen to induce apoptosis in MCF7 cells (Supplement Figure S3).

\section{ESR1 mutations induce ligand-independent and tamoxifen-resistant tumor growth with CDK2- dependent pS294 expression}

MCF7 expressing ER $\alpha$ activating mutations (Y537S, D538G) were produced by either transient transfection (Figure 3A) or knock-in (Figure 3B,C), and these sublines were evaluated for their ability to produce pS294 in the absence of ligand stimulation and for their dependence on CDK2. When expressed in parental MCF7 cells, both sets of activating mutations caused ligandindependent induction of pS118, pS167 and pS294, with only the latter being preventable by Dinaciclib, and none of these ER $\alpha$ phosphorylation events preventable by Palbociclib (Figure 3A,C). When the knock-in sublines, MCF7mutER(Y537S) and MCF7controlER(AAV), were inoculated into immunocompromised mice (not supplemented with E2) only the MCF7mutER(Y537S) subline showed ligand-independent tumor formation, and these tumors showed robust growth rates (Figure 3B) associated with constitutive formation of both $\mathrm{pS} 294$ and pS118 (Figure 3B inset).

In culture and in the absence of estrogen, these same sublines not only showed vastly different ligandindependent growth rates, but the more rapidly growing MCF7mutER(Y537S) cells were also minimally affected by Tamoxifen (TAM), while the much slower growing MCF7controlER(AAV) cells were reduced in number by TAM to below their initial culture inoculation density (Supplement Figure S4). To confirm its TAM resistance, the MCF7mutER(Y537S) subline was implanted subcutaneously into 38 nude mice (without E2 supplementation) in our in vivo study PTC1797, wherein 24 days following implantation 18 of the tumor bearing mice began daily TAM injections $(0.5 \mathrm{mg} \mathrm{sc})$ while 20 others received vehicle only injections. After 11 days of this treatment (day 35), there was no significant difference in the mean (+/- SEM) tumor volumes between the treatment arms, confirming the in vivo TAM resistance of this MCF7mutER(Y537S) subline. At this time point, 15 of the TAM treated mice and 6 of the control mice were 
selected to receive an additional 14 days of treatment as follows: continued daily TAM $(n=8), 30 \mathrm{mg} / \mathrm{kg}$ twice weekly ip Dinaciclib injections only $(n=6)$, or continued TAM plus twice weekly ip Dinaciclib $(n=7)$. As shown in Figure 4A (inset), the TAM only and Dinaciclib only treated groups continued to show growth increases in their tumor volumes, while the TAM plus Dinaciclib treated mice showed an average $20 \%$ regression from their day 35 tumor volumes.

Following these PTC1797 findings, a more definitive 6-arm PTC1854 xenograft study was undertaken with the MCF7mutER(Y537S) subline again implanted into nude mice without E2 supplementation (Figure 4B). Daily TAM injections were started for half the group beginning at day
9 while the other half received daily sc vehicle injections; at day 22, twice weekly ip treatments were begun for the 6 groups ( $n=8 \mathrm{mice} /$ group), each receiving vehicle, $30 \mathrm{mg}$ / $\mathrm{kg}$ of either Palbociclib or Dinaciclib, in addition to their daily (TAM or control) sc injections. At study day 31 and within 2-3 h of receiving their $4^{\text {th }}$ and final ip injection, animals were sacrificed and tumors resected and snap frozen for analysis. Despite considerable mouse-to-mouse variation in tumor volumes within each of the 6 treatment arms, PTC1854 confirmed the findings of PTC1797 by showing no significant differences in average final tumor volumes for TAM and control/vehicle-only treated mice, and no tumor inhibiting impact from either single agent Dinaciclib or Palbociclib. Remarkably, the combination
A.

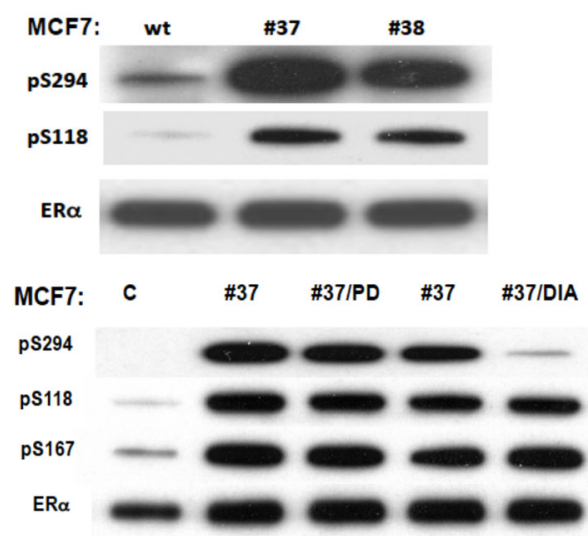

C.

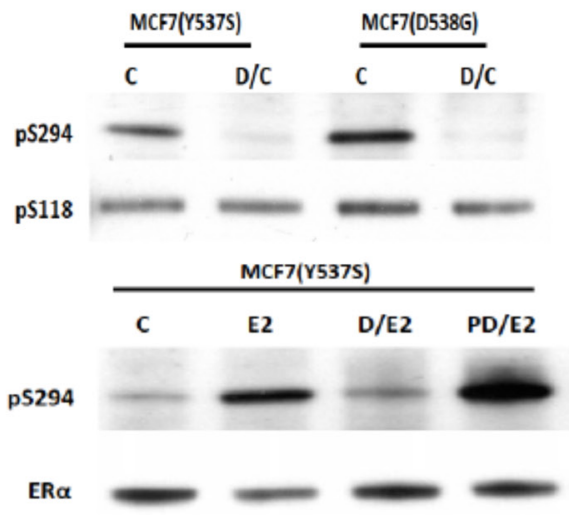

B.
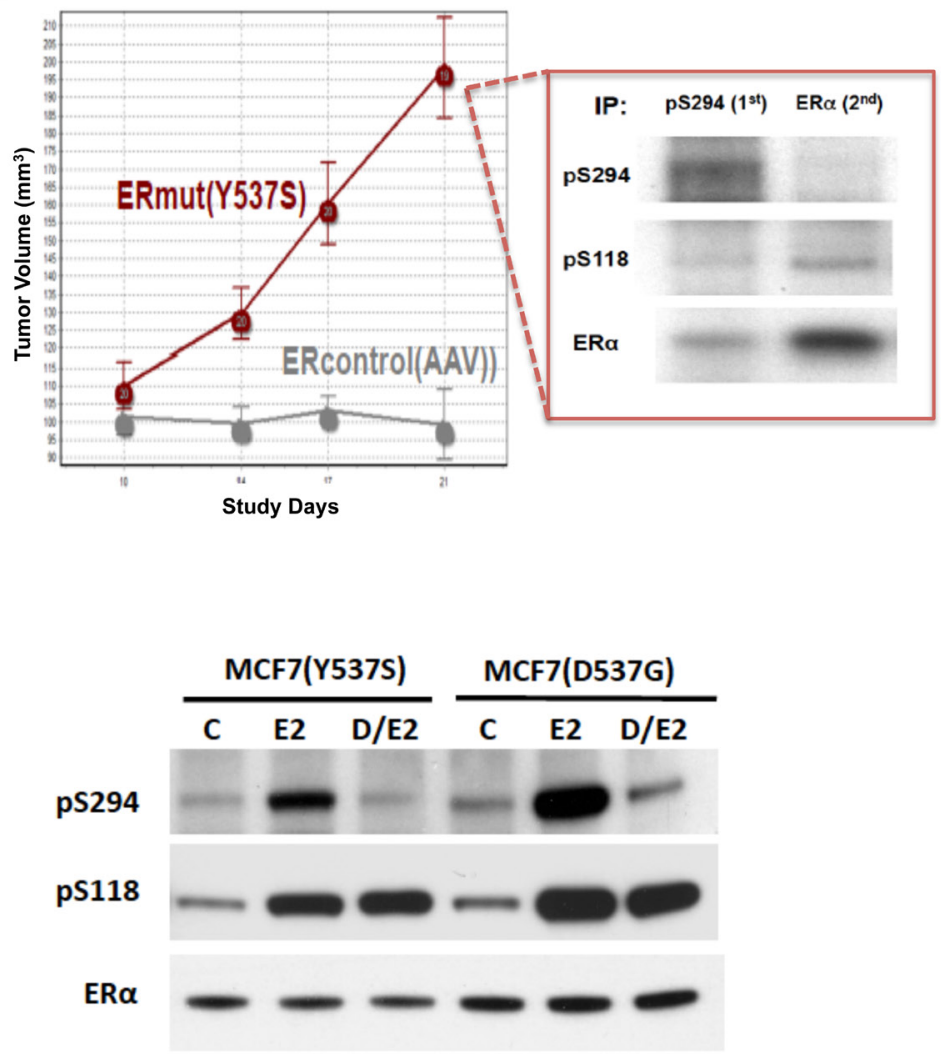

Figure 3: Transient and constitutive MCF7 overexpression of Y537S or D538G mutated ERa (mutER) induces ligandindependent tumorigenic growth with pS294 formation, prevented by the CDK2 inhibitor Dinaciclib but not by the CDK4/6 inhibitor Palbociclib. A. Following transient transfection of MCF7 cells with control (C or wt = pSG5-HEGO) or mutER expression vectors $(\# 37=$ Y 537S, \#38 = D538G), transfer to E2-free media (x 24-48 h), and subsequent culture treatment $(0.5 \mu \mathrm{M}$ x $60 \mathrm{~min})$ with either Dinaciclib (DIA) or Palbociclib (PD), cells were harvested, proteins extracted, ER $\alpha$ immunoprecipitated and immunoblotted for pS294, pS118, pS167, and total ER $\alpha$. B. Young nude mice were bilaterally implanted with knock-in MCF7 sublines (8 mice per subline), ERmut(Y537S) or ERcontrol(AAV), and observed for tumorigenic growth in the absence of exogenous E2 supplementation, with only the ERmut expressing cells showing E2-independent tumor growth. At 21 days, tumors were excised, protein extracted, immunoprecipitated first for pS294 ( $\left.1^{\text {st }} \mathrm{IP}\right)$ and then for remaining ER $\alpha$ ( $\left.2^{\text {nd }} \mathrm{IP}\right)$. Both IPs were immunoblotted for pS294, pS118, and total ER $\alpha$. C. Knockin MCF7 sublines, MCF7(Y537S), MCF7(D538G) and control MCF7(AAV), were serially passaged in E2 free media (C), transiently stimulated with E2 (10 $\mathrm{nM}$ x $20 \mathrm{~min})+/$ - pretreatment $(0.5 \mu \mathrm{M}$ x $60 \mathrm{~min})$ with Dinaciclib (D) or Palbociclib (PD) before cell harvest, protein extraction, ER $\alpha$ immunoprecipitation and immunoblotting for pS294, pS118, and total ER $\alpha$ as shown. 
treatments either arrested further tumor growth (TAM plus Palbociclib) or caused tumor volume regressions (TAM plus Dinaciclib), indicating a synergistic anti-tumor effect for the combination of agents that by themselves were unable to slow tumor growth (Figure 4B). To establish that the TAM treatments were having some biological effect on the tumors (including their stroma) despite the TAM resistance of MCF7mutER(Y537S) tumor cells, we showed that the TAM injections caused an upregulation in tumor TGF $\beta-1$ and VEGF-A protein expression (Supplement Figure S5), known to be part of an ER-independent TAM response [25-27]. Finally, to differentiate tumor responses to the TAM plus Palbociclib and TAM plus Dinaciclib treatment combinations, we showed that the latter were associated with loss of pS294 tumor expression not seen with the former treatment combination (Figure 4B inset).

\section{DISCUSSION}

Following our mass spectrometry discovery that the ER $\alpha$ hinge site at S294 is rapidly phosphorylated following ligand (E2, TAM) stimulation in a variety of ER-positive breast cancer cell lines [11], we developed a rabbit monoclonal antibody specific for $\mathrm{pS} 294$ that now makes available a powerful and facile analytical tool to interrogate endogenous induction of pS294 in relation to other intracellular $\mathrm{ER} \alpha$ phosphorylation sites. Using this new immunoreagent we confirmed that pS294 expression is detectable in primary human breast

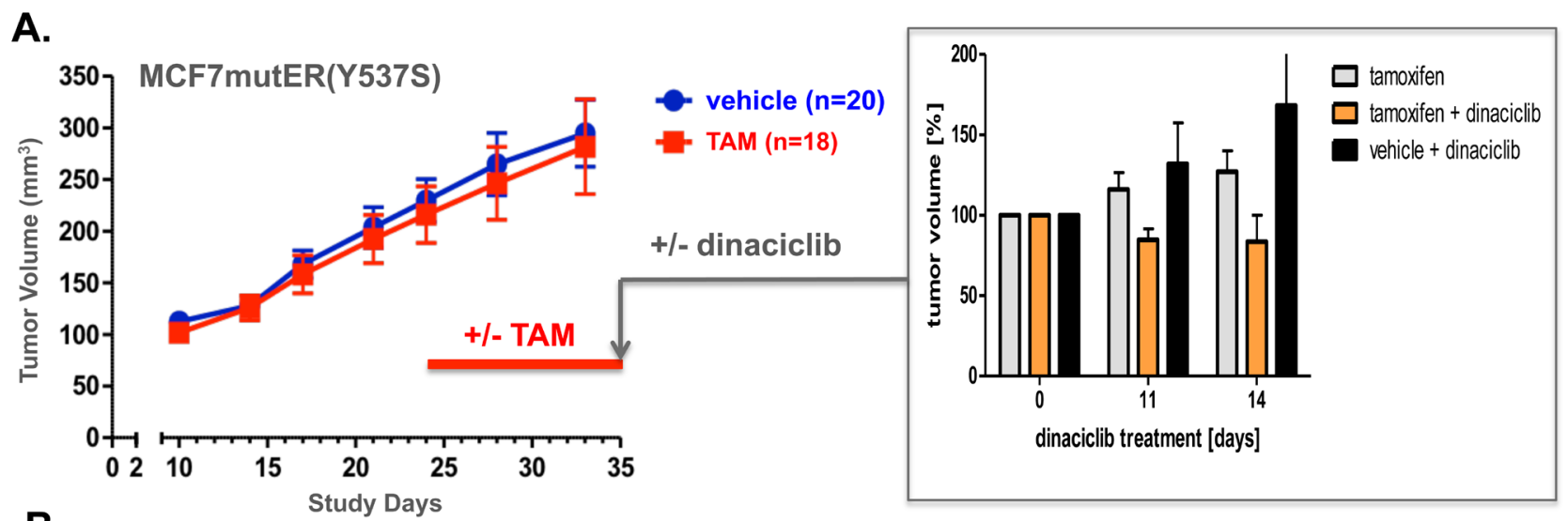

B.

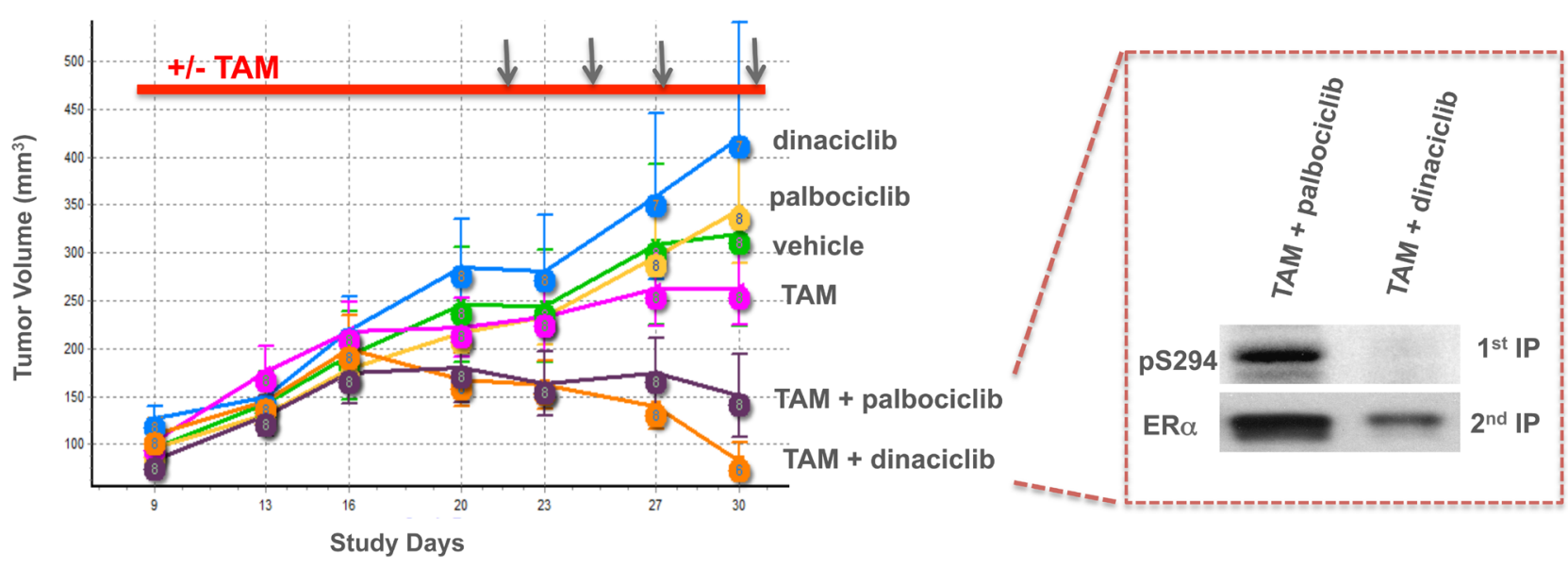

Figure 4: E2-independent MCF7mutER(Y537S) tumor xenografts are resistant to tamoxifen (TAM) but regress when TAM is combined with Dinaciclib, given at a dose and schedule that alone has no effect on tumor growth. A. In study PTC1797, MCF7mutER(Y537S) implanted nude mice showing tumor growth in the absence of exogenous E2 supplementation were allocated to begin treatment at day 24 with either daily sc $0.5 \mathrm{mg}$ tamoxifen citrate (18 mice, red bar) or vehicle (20 mice). At day 35 , mice with comparably sized tumors from each group were also begun with ip treatments receiving either vehicle or Dinaciclib (30 mg/kg) twice weekly over the next 14 days. Inset shows \% tumor volume change beyond day 35 for TAM $(n=8)$, Dinaciclib $(\mathrm{n}=6)$, and TAM + Dinaciclib $(n=7)$ treated tumors. B. In study PTC1854, MCF7mutER(Y537S) implanted nude mice (without E2 supplementation) showing tumor growth at day 8 were randomized into 6 treatment arms $(8$ mice/arm) to receive sc daily TAM $(n=18$, red bar $)$ or vehicle $(n=18)$ as in PTC1797, and at day 22 to begin ip treatments with vehicle $(\mathrm{n}=8)$ or $30 \mathrm{mg} / \mathrm{kg}$ of either Palbociclib or Dinaciclib as shown (vertical arrows). Inset shows representative IP/IB analysis of combination treated tumors harvested $2 \mathrm{~h}$ following final ip treatment, $1^{\text {st }}$ IP/IB for $\mathrm{pS} 294$ and $2^{\text {nd }} \mathrm{IP} / \mathrm{IB}$ for total $\mathrm{ER} \alpha$. 
tumors, albeit at seemingly lower levels than ER $\alpha$ AF-1 domain phosphorylation at S118. Unfortunately, the commercial withdrawal of the previously available antipS305 monoclonal (clone 124.9.4 from EMD Millipore) thwarted further validation of our earlier conclusion that ligand-activated pS294 induction and growth factor activated pS305 induction are usually mutually exclusive ER $\alpha$ phosphorylation events [11]. However, employing other commercially available and well validated antipS118 and anti-pS167 monoclonals to interrogate breast cancer cell line models expressing wildtype $\mathrm{ER} \alpha, \mathrm{pS} 294$ formation appears to be mechanistically independent from phosphorylation at these other sites in terms of kinetics, mode of receptor activation, and the kinase family mediating this phosphorylation. Of note, and unique to this hinge phosphorylation site, is our immuno-verification that pS294 formation is induced exclusively by agonistic $\mathrm{ER} \alpha$ ligand binding and mediated by a CDK family member different from all other kinases promoting ER $\alpha$ phosphorylation in response to ligand or growth factor stimulation.

Our present studies also support previous contentions that the ER $\alpha$ hinge region [28] and its phosphorylation at S294 [29] exert functional significance beyond their role in enabling full transcriptional execution of ER-dependent genes, namely, regulating the poorly understood mechanism of transcription-dependent ER degradation via the proteasomal pathway [30]. In experimental models, mutation at this S294 hinge site or enzymatic inhibition of its phosphorylation can increase intracellular ER $\alpha$ half-life and impair its ligandactivated proteasomal degradation within the nucleus [29]. Despite the efficient immunoprecipitating capacity of our anti-pS294 monoclonal, we have been unable to detect by chromatin immunoprecipitation (even following pretreatment with a proteasome inhibitor like MG132) DNA-binding of pS294 upon E2 stimulation at E2 inducible gene loci whereas increased DNA-binding by $\mathrm{ER} \alpha$ and $\mathrm{pS} 118$ following ligand stimulation are readily detectable at these loci (data not shown). These findings suggest a testable new hypothesis that ligand activated and DNA-bound ER $\alpha$ is first removed from the chromatin before being phosphorylated at S294, which tags the cistrome-removed receptor complex for reaction with an E3-ubiquitin ligase like $\mathrm{SCF}^{\mathrm{Skp} 2}$ for its ubiquitination and nuclear degradation $[29,30]$. In this regard, we now question earlier conclusions that $\mathrm{pS} 294$ formation results from the specific MAPK, p38 [29,30]. Rather, our studies support bioinformatic predictions that this hinge site is a CDK phosphorylation site; and our combination of CDK isoform-specific siRNA knock-down studies and comparison of a broad panel of CDK isoform-selective inhibitors indicate that $\mathrm{CDK} 2$ is the primary mediator of pS294 formation (Figure 2A, 2C). Although we have ruled out p38 involvement as a direct enzymatic mediator of pS294 induction (Supplement Figure S2A), studies in other cell systems showing that p38 activation can induce cyclin A2 leave open the possibility that extended p38 inhibitor treatment could ultimately inhibit CDK2 activity and pS294 formation by reducing cyclin A2 levels [31].

We also present a new model proposing that cyclin-dependent recruitment of CDK2 to the structurally activated domain E (LBD) of ER $\alpha$ enables pS294 formation (Figure 5). While other AF-1 domain phosphorylation events have been shown to occur by kinase recruitment via receptor coactivators like AIB1/

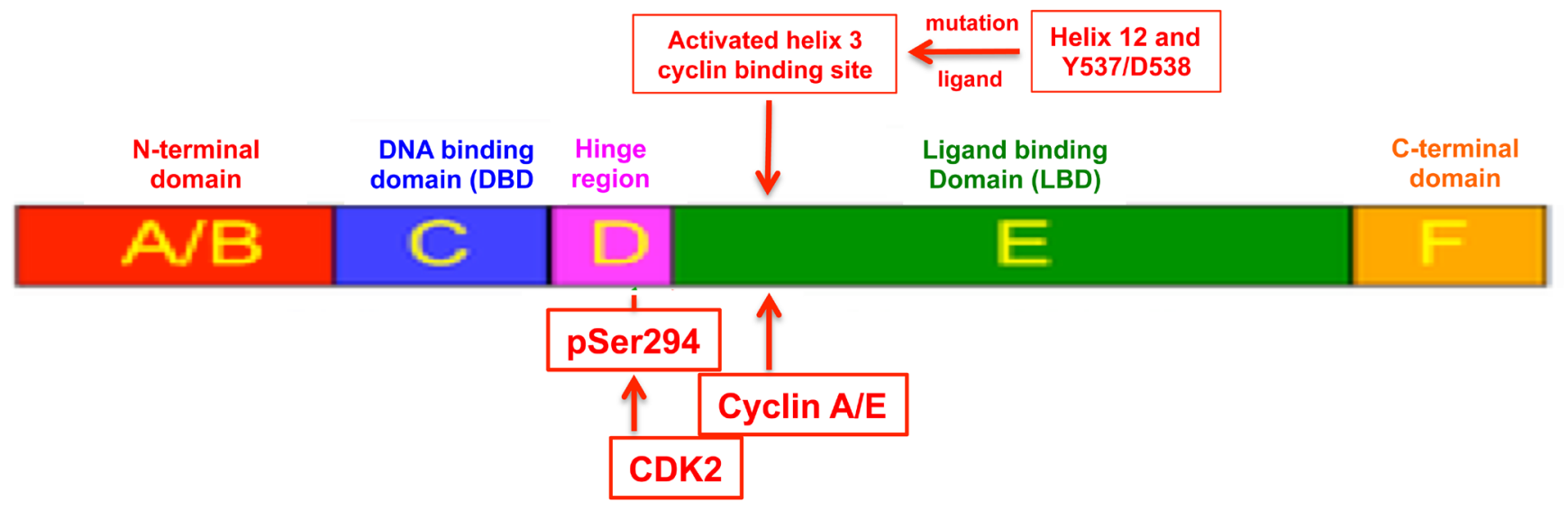

Figure 5: Schematic of proposed mechanism by which activation of the ER ligand binding domain (LBD) recruits cyclin A/E and CDK2 to phosphorylate its hinge S294 site. The most recent structural studies predict similarities in the repositioning of helix 12 in proximity to helix 3 [48], induced by either agonist binding within the LBD pocket or by acquisition of LBD mutations like Y537S and D538G in the absence of any ligand binding. We postulate that these LBD structural rearrangements may facilitate cyclin A/E binding to a highly conserved helix-3 RXL site (352-354), enabling receptor recruitment of CDK2 and its subsequent hinge phosphorylation at S294. 
SRC-3 [32] or by LBD residues that can directly dock to a specific kinase [33], our findings are the first to suggest that hinge phosphorylation at S294 first depends upon ligand binding or a mutation-associated structural change within the LBD, enabling cyclin A2 and/or E1 to bind to the highly conserved $\mathrm{R}^{352} \mathrm{X}^{353} \mathrm{~L}^{354}$ site (352-354) in helix 3, and thereby recruit and activate CDK2 for its phosphorylation of the adjacent hinge S294 site. It has long been recognized that cyclins can exert unexpected stimulatory and inhibitory functions, dependent or independent of their partner CDKs, on almost all steroid receptor family members, linking their transcriptional activities to cell cycle control and proliferation [34]. Unfortunately, such data with regard to ER $\alpha$ has so far been either sparse or mystifying. In one study, cyclin E was shown to influence the activities of AR and GR, but had no apparent effect on either ER $\alpha$ or PR [35]. In others, cyclin A in concert with CDK2 were reported to potentiate the activity of PR and ER, but by different mechanisms [36,37]. Potentially relevant to our model, cyclin A was shown to potentiate the ligand-independent activity of ER as well as enhance its tamoxifen induced activity [36]. While seemingly consistent with our model, this latter study was performed before the discovery of S294 phosphorylation and ascribed the cyclin A/CDK2 potentiation of ER $\alpha$ to phosphorylation at S104/S106 [36]. We have not only shown that a potent pan-CDK inhibitor capable of preventing S294 phosphorylation has no effect on MCF7 phosphorylation at S104/ S106 [11], these particular AF-1 sites are now thought to be primarily phosphorylated by MAPK and GSK3 kinases [38,39]. With our present understanding of the biological importance of pS294 formation under exclusive mechanistic control by CDK2, innovative breast cancer clinical opportunities become apparent given the therapeutic development of increasingly more specific CDK inhibitors [19-22] and the important recent findings of LBD hotspot mutations in ESR 1 arising during breast cancer metastatic progression and driving clinical resistance to both aromatase inhibitors and antiestrogens like tamoxifen [14-18].

Alongside recent approval and growing clinical use of CDK4/6 inhibitors like Palbociclib in combination with endocrine agents to treat metastatic ER-positive breast cancers, there have been parallel advancements in the clinical development of CDK2-selective inhibitors like Dinaciclib (Merck) and CYC065 (Cyclacel) for the treatment of hematopoietic and MYC-activated malignancies and potentially also breast cancers [19-22]. Armed with our structural model that ligand-activated ER recruits CDK2 for its phosphorylation at S294 (Figure 5 ), and given recent preclinical and clinical observations indicating that when ER $\alpha$ LBD helix 12 mutations occur at hotspot sites like Y537 (e.g. Y537S) and D538 (e.g. D538G) the expressed ERmut is constitutively activated in both a ligand-independent and ligand-excluding manner that can drive hormone-resistant metastatic progression of breast cancers, we predicted that ERmut expressing breast cancers would not only exhibit ligand-independent pS294 expression but also a susceptibility to CDK2 inhibitors not seen with CDK4/6 inhibitors. To address this prediction we developed two different isogenic experimental models of ERmut expressing breast cancers: transient transfection as well as gene knock-in with constitutive expression of either ERmut(Y537S) or ERmut(D538G) within ERpositive MCF7 breast cancer cells. Using these engineered models, we observed in vitro and in vivo that expression of either ERmut(Y537S) or ERmut(D538G), even in the presence of background wt ER $\alpha$ expression, produced ligand-independent and tamoxifen-resistant breast cancer growth (Figure 3, Supplement Figure S4). As well, we observed that this dysregulated ER-dependent growth was associated with constitutive pS294 expression that could be inhibited by a CDK2 inhibitor like Dinaciclib, but not by a CDK4/6 inhibitor like Palbociclib (Figures 3, 4).

In one particularly informative in vivo study (PTC1854) using the MCF7mutER(Y537S) model where E2-independent and TAM-resistant tumor growth was again observed, mice with well established tumors in addition to receiving daily tamoxifen also received parenteral injections of either Dinaciclib or Palbociclib, at equipotent doses previously shown to be well tolerated but unable as single agents to arrest growth of this tumor model (Figure 4B). Remarkably, both of these CDK inhibitors exhibited some degree of anti-tumor synergy in combination with TAM. The slightly greater antitumor effect apparent following TAM plus Dinaciclib was associated with loss of pS294 tumor expression, not seen in tumors given the TAM plus Palbociclib combination (Figure 4B). The potential for these two classes of CDK inhibitors to differentially interact with TAM may be due to their very different anti-mitotic mechanisms and phosphorylated substrates, as exemplified in our cell culture results on parental MCF7 cells wherein TAM plus Dinaciclib resulted in a marked degree of apoptosis not seen with the TAM plus Palbociclib combination (Supplement Figure S3). However, the more striking and potentially clinically relevant observation was the unexpected ability of TAM to induce an augmented or synergistic antitumor response to either type of small molecule CDK inhibitor. Addressing this interesting question of how TAM treatment, itself unable to arrest MCF7mutER(Y537S) tumor growth, when given in combination with a seemingly ineffective CDK inhibitor treatment regimen could result in tumor growth arrest or regression, we looked for evidence of an earlier reported TAM effect on ER-negative cells and tumors [25]. In keeping with those prior reports [26, 27], we observed that while the MCF7mutER(Y537S) tumors were not significantly growth arrested by TAM, they were clearly affected by the daily TAM treatments evidenced by their upregulated expression of TGF $\beta-1$ (stromal secreted 
isoform of TGF $\beta$ ) and VEGF-A (stromal vascular endothelial growth factor A) (Supplement Figure S5). Presently, we can only postulate that these stromal and/ or vascular effects of TAM altered the xenograft tumor physiology in such a way as to improve the intratumor bioavailability and efficacy of Dinaciclib and Palbociclib, enabling their respective CDK inhibiting differences to be seen in terms of tumor regression and pS294 expression. While observed only to date in our MCF7mutER(y537S) experimental model, future studies are needed to confirm that this synergistic phenomenon might also apply to all ER-positive breast tumors, whether or not they express ESR1 mutations.

In sum, our findings lead us to conclude that pS294 induction is essential for ER-dependent gene transcription and serves as a unique biomarker for both agonistic ligand and mutationally activated tumor ER $\alpha$. This induction and expression of pS294 in wt ER-positive or ERmut-positive breast cancers can be prevented by CDK2 inhibitors, but not by CDK4/6 inhibitors. While CDK4/6 inhibitors like Palbociclib in combination with TAM may potentially arrest the in vivo growth of ERmut expressing breast tumors, CDK2 inhibitors like Dinaciclib when given in combination with TAM may be more effective by inducing regressions in established ERmut expressing tumors. Altogether, these findings support further clinical evaluation of CDK2 inhibitors like Dinaciclib administered in combination with endocrine therapy as a potentially new treatment strategy against ESR1 mutation expressing breast cancers.

\section{MATERIALS AND METHODS}

\section{Reagents, antibodies, tumors, cells, and cell viability assay}

Under multi-institutional review board approval, 18 cryobanked samples $\left(-80{ }^{\circ} \mathrm{C},<100 \mathrm{mg}\right.$ wet weight, archived prior to 1999) from primary invasive breast tumors were provided by the Stiftung Tumorbank Basel (STB, now integrated within the pathology biobank of the University Hospital of Basel), all selected for their ER-positivity based on prior quantitative immunoassay (ER range: 47-387 fmol/mg protein). The human breast cancer cell line MCF7 was obtained from American Type Culture Collection (ATCC) and propagated under recommended conditions: $37^{\circ} \mathrm{C}, 5 \% \mathrm{CO}_{2}$ in Dulbecco's Modified Eagle's Medium (DMEM) supplemented with 5\% fetal bovine serum (FBS) and 1\% PenicillinStreptomycin (Life Technologies). The ER-positive human breast cancer cell line, SUM44, was provided by Stephen Ethier and passaged as previously described [40]. Phenol red-free media supplemented with L-glutamine was obtained from Invitrogen; charcoal stripped serum
(CSS) from Hyclone (Thermo Scientific); beta-estradiol (E2) and 4-hydroxytamoxifen (TAM) from SigmaAldrich. Cell viability assays were performed in multiwall white walled culture plates by CellTiter-Glo (Promega, Madison, WI) assay, as previously described [41]. ER $\alpha$ mouse monoclonal (clone F-10) and rabbit polyclonal (sc7207) antibodies were from Santa Cruz Biotechnology; pS118 and pS167 monoclonal antibodies were from Cell Signaling. A pS305 monoclonal antibody (clone 124.9.4), originally obtained from EMD Millipore, became commercially unavailable shortly after study initiation. The newly described rabbit monoclonal antibody to pSer294, was developed in collaboration with Epitomics/ Abcam (Burlingame, CA) using splenocyte clones (\#377 and \#65-3) derived from the same peptide-inoculated rabbits used to produce our previously described antipS294 antisera [11]. Other immunoprecipitating (IP)/ immunoblotting (IB) antibodies were commercially obtained as follows: anti-cyclin A2, anti-cyclin E1 and anti-TGF $\beta$-1 rabbit polyclonals, or anti-CDK2 and antiVEGF-A (SC7269) mouse monoclonals from Santa Cruz Biotechnology; and anti-PARP/cPARP rabbit monoclonal (\#9532) from Cell Signaling. CDK inhibitors including SNS (SNS-032), JNJ (JNJ7706621), DIA (Dinaciclib, SCH727965), PD (Palbociclib, PD0332991) and BMS (BMS-265246) were commercially obtained from Selleckchem, except for CYC065 which was kindly provided by Cyclacel (Dundee, UK). CDK inhibitors were dissolved in DMSO to produce a $10 \mathrm{mM}$ stock concentration that was stored at $-20{ }^{\circ} \mathrm{C}$. ON-TARGET plus SMART pool siRNA oligonucleotides to CDK1, CDK2 and CDK9 were obtained from Dharmacon (GE Dharmacon, Lafayette, $\mathrm{CO}$ ) and were transfected into MCF7 cells using Lipofectamine 2000 (ThermoFisher Scientific).

\section{MCF7 cell expression of Y537S and D538G mutated ERa}

MCF7 sublines transiently or constitutively expressing ER $\alpha$ activating mutations (Y537S or D538G) were produced by either Lipofectamine transfection or ESRl gene targeting (knock-in). For transient ectopic expression, MCF7 cells were lipofectamine transfected with either a wildtype ER $\alpha$ construct (wt: pSG5HEGO), or pSG5-HEGO constructs modified to express either Y537S (\#37) or D538G (\#38) mutations in the ER $\alpha$ DNA-binding domain (exon 10) using sequence verified plasmids and our previously described approach [11]; $24 \mathrm{~h}$ after culture transfection, cells were exposed to charcoal stripped media for an additional 24-48 h followed by cell lysate preparation for IP and IB. ESRI MCF7mutER knock-in sublines constitutively expressing either the Y537S or D538G mutation were produced using recombinant AAV vectors as previous described [42]. 
In brief, infectious AAV viral vectors harboring either the ESR1 Y537S or the D538G mutation were prepared in HEK-293T cells with approximately $10^{6}$ MCF7 cells used for each viral infection. Neomycin resistant clones were isolated and screened via a modified PCR strategy then exposed to Cre-expressing recombinant adenovirus to remove the neomycin cassette [43]. All isolated clones were confirmed by Sanger sequencing and droplet digital PCR of genomic DNA and cDNA to ensure the clones harbored the intended ESR1 knock-in mutation as a single copy with expression equal to the remaining wild type ESR1 allele. Primer sequences for PCR amplification, mutagenesis, targeting and sequencing are shown in Supplement Table S1.

\section{Tumorigenicity and treatment of xenografted MCF7mutER tumors}

Animal studies reported here (PTC1797, PTC1854) were conducted under IACUC approval (AN092211) in the UCSF Cancer Center's Preclinical Therapeutics Core (PTC). MCF7mutER (Y537S, D538G, AAV controls) knock-in sublines were first expanded in vitro and then subcutaneously (sc) injected to evaluate xenograft tumor growth. In brief, NCR nu/nu athymic female mice (6 weeks old; Taconic Farms, Germantown, NY) were implanted with $1 \times 10^{7} \mathrm{MCF} 7$ mutER cells sc in the upper back area as a $0.1 \mathrm{~mL}$ suspension in serum free media 1:1 with matrigel. Tumor growth was measured by caliper along the largest (length) and smallest (width) axes as well as body weights were determined twice a week. Tumor volumes were calculated using the following formula: tumor volume $=[($ length $) \times($ width $) \times($ width $)] /$ 2. Approximately 8 days after tumor implantation (mean tumor volume $=100 \mathrm{~mm}^{3}$ ) animals were randomized into two primary treatment groups (Tamoxifen vs. vehicle), and approximately 14 days after first treatment initiation (study day $\sim 34$, when mean tumor volumes of vehicle and single agent treated mice reached $\sim 300 \mathrm{~mm}^{3}$ ), mice were further divided into additional treatment groups as indicated (+/- Dinaciclib, +/- Palbociclib), and these secondary treatments carried for $\sim 14$ days. Tamoxifen (TAM) citrate was prepared in a $10 \mathrm{mg} / \mathrm{ml}$ suspension in peanut oil vehicle and either TAM $(0.5 \mathrm{mg})$ or vehicle alone was delivered sc daily as previously studied [44, 45]. Dinaciclib (30 mg/kg), Palbociclib (30 mg/kg), or vehicle (20\% hydroxypropyl-b-cyclodextrin) was delivered by intraperitoneal injection (ip) every 3 days on the indicated study days, dosing based on prior studies [46, 47] and preliminary experiments establishing in vivo tolerance of tumor-bearing mice ( $<10 \%$ loss of body weight) to repeated ip Dinaciclib doses when given in combination with daily sc TAM. At study conclusion, all animals were euthanized and tumors resected and snap frozen (-| || || |C) within 2-3 $\mathrm{h}$ following the final treatment dose.

\section{Tumor cell lysates, protein immunoprecipitation and immunoblotting}

Monolayer cell cultures were harvested in ice cold lysis buffer [100 mmol/L NaCl, $20 \mathrm{mmol} / \mathrm{L}$ Tris (pH 7.5), 0.5\% IGEPAL-630, 1 tablet/10 mL PhosSTOP (Roche Applied Science), $320 \mathrm{nmol} / \mathrm{L}$ okadaic acid, and 1 tablet/10 mL Roche mini-complete protease inhibitor cocktail (Roche Applied Science)]; tumors and xenografts were first pulverized under liquid nitrogen and then sonicated in lysis buffer. To prepare isolated nuclei, cells were first lysed in low salt buffer $(10 \mathrm{mM}$ Tris $\mathrm{pH}$ 7.5, $50 \mathrm{mM} \mathrm{NaCl}, 0.4 \%$ NP40 plus above protease and phosphatase inhibitors; pelleted cell free nuclei were resuspended in nuclear extraction buffer $(0.4 \mathrm{M} \mathrm{KCl}, 20$ $\mathrm{mM}$ Hepes $\mathrm{pH} 7.5,1.5 \mathrm{mM} \mathrm{MgCl}$ and $10 \%$ glycerol) for $20 \mathrm{~min}$ and residual chromatin removed by centrifugation. Protein from the resulting cleared supernatant was IP by the addition of $8 \mu \mathrm{l}$ of F-10 anti-ER $\alpha$ antibody (at $0.2 \mathrm{mg} /$ ml) with $15 \mu \mathrm{L}$ Protein G Sepharose 4 Fast Flow beads (GE Healthcare) and incubated with slow rotation at $4{ }^{\circ} \mathrm{C}$ for $6 \mathrm{~h}$. Beads were then pelleted washed 3 times in wash buffer (125 mmol/L NaCl, $20 \mathrm{mmol} / \mathrm{L}$ Tris, $\mathrm{pH} 7.5$, and $0.35 \%$ IGEPAL). IP samples were then suspended in Laemmli loading buffer and analyzed by IB as previously described [11]. Immunoblot film images were scanned and imported into a ChemiDoc XRS system (Bio-Rad), and utilizing the ChemiDoc analysis software the area around each immunoblot band of interest was selected and quantified, with the intensity of each band minus the background intensity used to quantify protein levels.

\section{Semiquantitative reverse-transcription PCR}

As previously described [11], total RNA was harvested using Trizol followed by treatment with DNA-free (Ambion, Austin, TX) according to the manufacturer's specifications to remove potentially contaminating DNA. Reversed transcription was performed using oligo dT priming of $0.5 \mu \mathrm{g}$ RNA per sample condition with SuperScript II (Invitrogen, Carlsbad, CA) according to manufacturer's specifications. PCR reactions used $1 \mu \mathrm{l}$ aliquots from the RT reactions with Pfu polymerase (New England Biolabs, Ipswich, MA). Reaction conditions consisted of annealing at $60^{\circ} \mathrm{C}$ for $30 \mathrm{sec}$, extension at $72^{\circ} \mathrm{C}$ for $25 \mathrm{sec}$ and denaturation at $96^{\circ} \mathrm{C}$ for $10 \mathrm{sec}$ with identically prepared reactions subjected to 24,26 or 28 PCR cycles. PCR products were electrophoresed on $8 \%$ polyacrylamide gels, stained with eithidum bromide, photographed and quantified by densitometry using a GS-710 Calibrated Imaging Densitometer (Bio-Rad, Hercules, CA). Primers included: AREG (Amphiregulin) 170bp 5'aaaaagggaggcaaaaatgg3' (forward), 5'tcatggacttttccccaca3' (reverse); EGR3 238bp 5'gcagcatggtcttgactgaa3' (forward), 
5' ccccctttccactagagtcc3' (reverse);

$221 \mathrm{bp} \quad 5$ 'ctagtcaagtgegtccacga3'

5'ggacacaccacagcacaaac3' (reverse);

234bp 5'cgaatttggctacagcaacagg3'

5 'gtacatgacaaggtgcggctc3' (reverse).

\section{Abbreviations}

ER $\alpha$, estrogen receptor alpha; ERmut, mutationally activated ER $\alpha$; CDK, cyclin-dependent kinase; ERpS294 (or pS294), ER $\alpha$ phosphorylation at serine-294.

\section{ACKNOWLEDGMENTS}

We thank Mina Muthurajah for her dedicated technical assistance on this project while at the Buck Institute. We also thank Dr. David Blake for facilitating our project procurement of CYC065, and Dr. Stephen Ethier for providing the ER-positive human breast cancer cell line, SUM44.

\section{CONFLICTS OF INTEREST}

Gary Scott \& Christopher Benz: Potential royalty payments for anti-ERpS294 rabbit monoclonal licensed for commercial sale to Abcam by Buck Institute for Research on Aging.

David Chu \& Ben Park: Potential royalty payments for knock-in MCF7/ERmut cell lines licensed by Johns Hopkins University for commercial sale to Horizon Discovery, where Ben Park is also a paid scientific advisor.

\section{GRANT SUPPORT}

National Institutes of Health (NIH) sponsored grants R01-CA071468 and U24-CA143858 in support of CCB; and the Avon Foundation and Eddie and Sandra Garcia Foundation grants in support of BHP.

\section{REFERENCES}

1. Deroo BJ, Korach KS. Estrogen receptors and human disease. J Clinical Investigation. 2006; 116: 561-570.

2. Hewitt SC, Winuthayanon W, Korach KS. What's new in estrogen receptor action in the female reproductive tract. J. Molecular Endocrinology. 2016; 56: R55-R71.

3. Le Romancer M, Poulard C, Cohen P, Sentis S, Renoir JM, Corbo L. Cracking the estrogen receptor's posttranslational code in breast tumors. Endocrine Reviews. 2011; 32: 597622.

4. Lannigan DA. Estrogen receptor phosphorylation. Steroids. 2003; 68: 1-9.

5. Weigel NL, Moore NL. Steroid receptor phosphorylation: a key modulator of multiple receptor functions. Molecular
Endocrinology. 2007; 21: 2311-2319.

6. Atsriku C, Britton DJ, Held JM, Schilling B, Scott GK, Gibson BW, Benz CC, Baldwin MA. Systematic mapping of posttranslational modifications in human estrogen receptor- $\alpha$ with emphasis on novel phosphorylation sites. Molecular \& Cellular Proteomics. 2009; 8: 467-480.

7. Anbalagan M, Rowan BG. Estrogen receptor alpha phosphorylation and its functional impact in human breast cancer. Molecular and Cellular Endocrinology. 2015; 418: 264-272.

8. Kok M, Holm-Wigerup C, Hauptmann M, Michalides R, Stal O, Linn S, Landberg G. Estrogen receptor- $\alpha$ phosphorylation at serine-118 and tamoxifen response in breast cancer. J Natl Cancer Inst. 2009; 101:1725-1729.

9. Jiang J, Sarwar N, Peston D, Kulinskaya E, Shousha S, Coombes RC, Ali S. Phosphorylation of estrogen receptor- $\alpha$ at Ser167 is indicative of longer disease-free and overall survival in breast cancer patients. Clin Cancer Res. 2007; 13: 5769-5776.

10. Holm C, Kok M, Michalides R, Fles R, Koornstra RH, Wesseling J, Hauptmann M, Neefjes J, Peterse JL, Stal O, Landberg G, Linn SC. Phosphorylation of the oestrogen receptor alpha at serine 305 and prediction of tamoxifen resistance in breast cancer. J Pathol. 2009; 217: 372-379.

11. Held JM, Britton DJ, Scott GK, Lee EL, Schilling B, Baldwin MA, Gibson BW, Benz CC. Ligand binding promotes CDK-dependent phosphorylation of ER-alpha on hinge serine 294 but inhibits ligand-independent phosphorylation of serine 305. Mol Cancer Res. 2012; 10: 1120-1132.

12. Murphy LC, Seekallu SV, Watson PH. Clinical significance of estrogen receptor phosphorylation. Endocrine-Related Cancer. 2011; 18: R1-R14.

13. de Leeuw R, Neefjes J, Michalides R. A role for estrogen receptor phosphorylation in the resistance to tamoxifen. Int. J. Breast Cancer. 2011; 2011: 1-10.

14. Oesterreich S, Davidson NE. The search for ESR1 mutations in breast cancer. Nature Genetics. 2013; 45: 1415-1416.

15. Segal CV, Dowsett M. Estrogen receptor mutations in breast cancer- new focus on an old target. Clin Cancer Res. 2014; 20: 1724-1726.

16. Thomas C, Gustafsson JA. Estrogen receptor mutations and functional consequences for breast cancer. Trends in Endocrinology \& Metabolism. 2015; 26: 467-476.

17. Jordan VC, Curpan R, Maximov PY. Estrogen receptor mutations found in breast cancer metastases integrated with the molecular pharmacology of selective ER modulators. J Natl Cancer Inst. 2015; 107: 1-10.

18. Fanning SW, Mayne CG, Venkatasubramanian D, Carlson KE, Martin TA, Novick SJ, Toy W, Green B, Panchamukhi S, Katzenellenbogen BS, Tajkhorshid E, Griffin PR, Shen Y, et al. Estrogen receptor alpha somatic mutations Y537S and D538G confer breast cancer endocrine resistance by 
stabilizing the activating function-2 binding conformation. eLIFE. 2016; 5:312792.

19. Vidula N, Rugo HS. Cyclin-dependent kinase $4 / 6$ inhibitors for the treatment of breast cancer: a review of preclinical and clinical data. Clinical Breast Cancer. 2016; 16: 8-17.

20. Lapenna S, Giordano A. Cell cycle kinases as therapeutic targets for cancer. Nature Reviews Drug Discovery. 2009; 8: 547-566.

21. Torres G, Echavarria I, Lobo M, Marquez-Rodas I, Martin M. Cyclin kinase inhibitors in breast cancer: from bench to bedside. Curr Breast Cancer Rep. 2014; 6: 79-87.

22. Criscitiello C, Viale G, Esposito A, Curigliano G. Dinaciclib for the treatment of breast cancer. Expert Opin Investig Drugs. 2014; 23: 1305-1312.

23. Conroy A, Stockett DE, Walker D, Arkin MR, Hoch U, Fox JA, Hawtin RE. SNS-032 is a potent and selective CDK 2, 7 and 9 inhibitor that drives target modulation in patient samples. Cancer Chemother Pharmacol. 2009; 64: 723-732.

24. Blake DG, MacKay C, Frame S, Zheleva D. CYC065, a novel CDK2/9 inhibitor: Molecular basis for clinical development in basal-like triple-negative breast cancer. [abstract]. In: Proceedings of the Thirty-Eighth Annual CTRC-AACR San Antonio Breast Cancer Symposium: 2015 Dec 8-12; San Antonio, TX. Philadelphia (PA): AACR; Cancer Res. 2016; 76: Abstract \# P5-03-10.

25. Manna S, Holz MK. Tamoxifen action in ER-negative breast cancer. Sign Transduct Insights. 2016; 5: 1-7.

26. Butta A, MacLennan K, Flanders KC, Sacks NPM, Smith I, McKinna A, Dowsett M, Wakefield LM, Sporn MB, Baum $\mathrm{M}$, Colletta AA. Induction of transforming growth factor $\beta 1$ in human breast cancer in vivo following tamoxifen treatment. Cancer Res. 1992; 52: 4261-4264.

27. Arias-Pulido H, Chaher N, Gong Y, Qualls C, Vargas J, Royce M. Tumor stromal vascular endothelial growth factor A is predictive of poor outcome in inflammatory breast cancer. BMC Cancer. 2012; 12: 298.

28. Berry NB, Fan M, Nephew KP. Estrogen receptor- $\alpha$ hingeregion lysines 302 and 303 regulate receptor degradation by the proteasome. Molecular Endocrinology. 2008; 22: 15351551.

29. Bhatt S, Xiao Z, Meng Z, Katzenellenbogen BS. Phosphorylation by p38 mitogen-activated protein kinase promotes estrogen receptor $\alpha$ turnover and functional activity via the SCFskp2 proteasomal complex. Mol Cell Biology. 2012; 32: 1928-1943.

30. Zhou W, Slingerland JM. Links between oestrogen receptor activation and proteolysis: relevance to hormone-regulated cancer therapy. Nature Rev Cancer. 2014; 14: 26-38.

31. Zhang J, Pan $\mathrm{C}, \mathrm{Xu} \mathrm{T}$, Niu Z, Ma C, Xu C. Interleukin 18 augments growth ability via $\mathrm{NF}-\kappa \mathrm{B}$ and p38/ATF2 pathways by targeting cyclin $\mathrm{B} 1$, cyclin $\mathrm{B} 2$, cyclin $\mathrm{A} 2$, and Bcl-2 in BRL-3A rat liver cells. Gene. 2015; 563: 45-51.

32. Park KJ, Krishnan V, O'Malley BW, Yamamoto Y, Gaynor RB. Formation of an IKK $\alpha$-dependent transcription complex is required for estrogen receptor-mediated gene activation. Molecular Cell. 2005; 18: 71-82.

33. Clark DE, Poteet-Smith CE, Smith JA, Lannigan DA. Rsk2 allosterically activates estrogen receptor $\alpha$ by docking to the hormone-binding domain. The EMBO J. 2001; 20: 34843494.

34. Weigel NL, Moore NL. Cyclins, cyclin dependent kinases, and regulation of steroid receptor action. Molecular \& Cellular Endocrinology. 2007; 265-266: 157-161.

35. Yamamoto A, Hashimoto Y, Kohri K, Ogata E, Kato S, Ikeda K, Nakanishi M. Cyclin E as a coactivator of the androgen receptor. J Cell Biol. 2000; 150: 873-880.

36. Rogatsky I, Trowbridge JM, Garabedian MJ. Potentiation of human estrogen receptor a transcriptional activation through phosphorylation of serines 104 and 106 by the cyclin A-CDK2 complex. J Biol Chem. 1999; 274: 2229622302.

37. Narayanan R, Adigun AA, Edwards DP, Weigel NL. Cyclin-dependent kinase activity is required for progesterone receptor function: novel role for cyclin A/ $\mathrm{Cdk} 2$ as a progesterone receptor coactivator. Mol Cell Biol. 2005; 25: 264-277.

38. Thomas RS, Sarwar N, Phoenix F, Coombes RC, Ali S. Phosphorylation at serines 104 and 106 by Erk1/2 MAPK is important for estrogen receptor- $\alpha$ activity. J Mol Endocrinology. 2008; 40: 173-184.

39. Medunjanin S, Hermani A, De Servi B, Grisouard J, Rincke G, Mayer D. Glycogen synthase kinase-3 interacts with and phosphorylates estrogen receptor $\alpha$ and is involved in the regulation of receptor activity. J Biol Chem. 2005; 280: 33006-33014.

40. Irish JC, Mills JN, Turner-Ivey B, Wilson RC, Guest ST, Rutkovsky A, Dombkowski A, Kappler CS, Hardiman G, Ethier S. Amplification of WHSC1L1 regulates expression and estrogen-independent activation of ER $\alpha$ in SUM44 breast cancer cells and is associated with ER $\alpha$ overexpression in breast cancer. Mol Oncol. 2016; 10: 850-865.

41. Wilson-Edell KA, Yevtushenko MA, Rothschild DE, Rogers AN, Benz CC. mTORC1/C2 and pan-HDAC inhibitors synergistically impair breast cancer growth by convergent AKT and polysome inhibiting mechanisms. Breast Cancer Res Treat. 2014; 144: 287-298.

42. Gustin JP, Karakas B, Weiss MB, Abukhdeir AM, Lauring J, Garay JP, Cosgrove D, Tamaki A, Konishi H, Konishi Y, Mohseni M, Wang G, Rosen DM, et al. Knockin of mutant PIK3CA activates multiple oncogenic pathways. Proc Natl Acad Sci. USA. 2009; 106: 2835-2840.

43. Konishi H, Karakas B, Abukhdeir AM, Lauring J, Gustin JP, Garay JP, Konishi Y, Gallmeier E, Bachman KE, Park $\mathrm{BH}$. Knock-in of mutant K-ras in nontumorigenic human epithelial cells as a new model for studying K-ras mediated transformation. Cancer Res. 2007; 67: 8460-8467.

44. Benz CC, Scott GK, Sarup JC, Johnson RM, Tripathy D, Coronado E, Shepard HM, Osborne CK. Estrogen- 
dependent, tamoxifen-resistant tumorigenic growth of MCF-7 cells transfected with HER2/neu. Breast Cancer Res. Treat. 1992; 24: 85-95.

45. Shou J, Massarweh S, Osborne CK, Wakeling AE, Ali S, Weiss H, Schiff R. Mechanisms of tamoxifen resistance: increased estrogen receptor-HER2/neu cross-talk in ER/ HER2-positive breast cancer. J Natl Cancer Inst. 2004; 96 : 926-935.

46. Parry D, Guzi T, Shanahan F, Davis N, Prabhavalkar D, Wiswell D, Seghezzi W, Paruch K, Dwyer MP, Doll R, Nomeir A, Windsor W, Fischmann T, et al. Dinaciclib (SCH727965), a novel and potent cyclin-dependent kinase inhibitor. Mol Cancer Ther. 2010; 9: 2344-2353.

47. Horiuchi D, Kusdra L, Huskey NE, Chandriani S, Lenburg ME, Gonzalez-Angulo AM, Creasman KJ, Bazarov AV, Smyth JW, Davis SE, Yaswen P, Mills GB, Esserman LJ,
Goga A. MYC pathway activation in triple-negative breast cancer is synthetic lethal with CDK inhibition. J Exp Med. 2012; 209: 679-696.

48. Fanning SW, Mayne CG, Dharmarajan V, Carlson KE, Martin TA, Novick SJ, Toy W, Green B, Panchamukhi S, Katzenellenbogen BS, Tajkhorshid E, Griffen PR, Shen Y, et al. Estrogen receptor alpha somatic mutations Y537S and D538G confer breast cancer endocrine resistance by stabilizing the activating function-2 binding conformation. eLIFE. 2016; 5:e12792. 